\title{
Equity-Minded Faculty Development: An Intersectional Identity-Conscious Community of Practice Model for Faculty Learning ${ }^{1}$
}

\author{
Kimberly A. Costino
}

\begin{abstract}
Equity-minded institutional transformation requires robust faculty learning. Research has shown that the single most important factor in student success is faculty interaction. Positive, supportive, and empowering faculty interaction is particularly important to the success of female students, poor and working class students, and students of color, but most faculty are not prepared to offer the kind of support that has been shown to be most effective for marginalized students. If institutions are serious about equity and about transformation, then they are obligated to provide professional development that will support the learning necessary for faculty to fulfill these important roles and to support faculty financially or by buying their time to participate in it. An effective way to do this is to align such professional development with the urgent needs of the campus and their related campus-wide initiatives. This article describes a community of practice model of identity-conscious professional development that engages faculty in a scholarly approach to the science of learning and evidence-based teaching and curriculum development while at the same time insistently and consistently incorporating critical reflection on and exploration of how systems of power and oppression impact learning. We believe this faculty engagement is key to transforming our institution into a more equitable and inclusive learning environment for students and faculty alike.
\end{abstract}

Keywords: faculty development; faculty communities of practice; identity-consciousness; learning as social participation; equity-minded institutional transformation

\section{The Role of Faculty and Faculty Learning in Equity-Minded Institutional Transformation}

For more than ten years, the American Association of Colleges and Universities (AAC\&U) has been working to help colleges and universities throughout the country transform themselves in ways that will better prepare all students to meet the complex demands of the $21^{\text {st }}$ century. Toward this end, the association has developed and promoted "Essential Learning Outcomes," as a "guiding vision" for learning in higher education, emphasizing the need for ongoing, authentic

${ }^{1}$ Participation in multiple communities of practice has helped me, in collaboration with many others, to develop the program for faculty professional learning described here. I was first immersed in a community of practice model of professional learning in my work with Nika Hogan and the California Community College Success Network (3CSN) on the Threshold Project and Reading Apprenticeship Communities of Practice. Since then, I have worked with my colleagues on my own campus to adapt this statewide model for CSUSB's transformation work. My most significant CSUSB collaborators include Davida Fischman, Kirsten Fleming, and Qiana Wallace. All of these colleagues have made significant contributions to the work described here. I am grateful for the opportunity to work with and learn from them all. 
assessment of student learning at all levels of the university. This information supported the implementation of high-impact practices that have been shown to increase student engagement, to foster deep learning in students, and to therefore improve retention and graduation rates. More recently, it has launched the LEAP Challenge, which asks universities to embed "signature work" into the curriculum in an effort to prepare students to productively address the unscripted problems that will characterize the world in the $21^{\text {st }}$ century and beyond. As Carol Geary Schneider (2015), the AAC\&U president who launched this initiative, put it,

The best way to prepare students to create solutions in a complex world, the LEAP Challenge affirms, is to actively involve students in working on problem-centered inquiry from the time they enter college (and, optimally, before) until they successfully complete their degrees - two-year and four-year degrees alike. The "challenge," then, is to prepare every college student-yes, every one of them-to engage complex problems and questions and to ensure that they develop facility in evidence-based inquiry, analysis, and decision-making.

Schneider's emphasis on "every" college student, as well as the organization's oft-used phrase “inclusive excellence,” highlights AAC\&U's efforts to encourage colleges and universities to make attention to equity central to their transformation work.

This means focusing explicitly on fostering both the willingness and the ability to understand the historical and systemic roots of students' differing needs, and to respond effectively to those needs in ways that will ensure equality in outcomes and opportunity, as well as in access.

Indeed, much of the recent research and scholarship in higher education argues that improving student success, fostering deeper learning in students and increasing retention and graduation rates, cannot be achieved unless we create more equitable and inclusive institutions (Elrod \& Kezar, 2016; Pendakur 2016; McNair et al., 2016). A substantial body of research indicates that the most significant factor in student success, particularly for students who do not enter the university with the kind of social and cultural capital most valued in academia, is faculty-student interaction (Bensimon, 2007; Kezar, 2014; Pendakur, 2016; Umbach \& Wawrzynski, 2005). With respect to classroom practice, research indicates that holding students to high academic standards, engaging them in culturally-responsive, student-centered, problem-centered, activelearning strategies, and providing ongoing formative assessment about their progress on learning goals and outcomes can have a significant impact on student learning and success. It also suggests that interactions outside the classroom, such as working on research projects, serving on committees together and chatting informally can be equally impactful on retention. According to Pendakur (2016) the key ingredient in all of these interactions is faculty members' willingness and ability to serve as “empowering agents,” in students' academic lives.

[empowering agents] call into question the race-blind, gender-blind standards of a meritocracy by naming and challenging the extant stratification in U.S. higher education [and who] leverage their positions and capacities to either directly transmit or negotiate access to highly prized, key forms of institutional resources, support, and opportunities while concurrently working to alter the institution from the inside. 
Building from the work of Bensimon (2007), Pendakur (2016) argues that serving as successful empowerment agents entails critically reflecting on one's own position, power, privilege, experiences and beliefs, challenging deficit-minded representations of students, and recognizing, acknowledging, and building from the cultural and community wealth students bring with them to our institutions.

While Pendakur (2016) makes a convincing case for the effectiveness of these empowerment agents within his broader "intersectional identity-conscious approach to student success," the ability to successfully serve in this capacity (and to integrate this approach in ways that are helpful to marginalized students) requires sensitivity, support, and expertise that faculty members do not necessarily acquire as part of their academic preparation. Indeed, as Bensimon (2007) points out, "institutions have difficulties producing equitable educational outcomes partly because practitioners lack the specialized knowledge and expertise to recognize the racialized nature of the collegiate experience for African-American and Latina/o students and adjust their practices accordingly" (446). We are, therefore, obligated to provide the kind of professional development that will support faculty to develop this sensitivity and expertise as part of the work of institutional transformation.

The purpose of this article is to describe a "community of practice" model (Wenger 2000) of identity-based (Pendakur 2016) professional development being implemented at California State University, San Bernardino (CSUSB) that is intended to foster this kind of sensitivity and expertise among its faculty. Rooted in the theory of learning as participation, communities of practice are groups of people who interact on an on-going basis, within a series of loosely structured learning environments, in order to deepen their knowledge about a particular topic. Identity-based approaches to professional development seek to deepen participants' understanding of their own and others' identities in an effort to foster more equitable and inclusive learning environments. CSUSB's identity-conscious community of practice leverages existing institutional initiatives and relies heavily on a faculty learning community model for depth of learning, while simultaneously offering multiple levels or tiers of participation in the community of practice as a whole. Building from the assumption that because faculty are scholars, they must be engaged in a scholarly approach to learning, the model positions and engages faculty as learners, first by asking them to inquire into the science of learning and disciplinary habits of mind, and then recursively extending this inquiry into equity, inclusion, and exclusion. In so doing, it embeds attention to, and serves as a model for, the kind of curriculum and pedagogy that research suggests fosters inclusive excellence.

The curriculum and content are structured in ways that reflect what research tells us about how people learn (Bransford, et al., 1999; Kober, N. 2015). It focuses on helping faculty think more metacognitively about - to become more consciously aware of - their own disciplinary ways of thinking and practicing and how to effectively apprentice students into these ways of thinking and doing (Cousin, 2006; Meyer and Land, 2006; Middendorf \& Pace, 2004). And it consistently and insistently incorporates critical reflection on and exploration of how racism, sexism, and other systems of power and oppression impact learning, exposing the ways that our interactions with students both in and outside the classroom can either work to create and maintain or to challenge and dismantle institutional and cultural inequities (Bensimon, 2007; McNair et al, 2016; Pendakur, 2016; Steele, 2010; Yosso 2005). Taken together, these strategies are gradually 
building a campus culture that nourishes ongoing and transformative faculty learning about how to create more equitable and inclusive learning environments for students.

\section{Institutional Context}

CSUSB, a federally designated Hispanic-Serving Institution, is one of 23 institutions in the California State University (CSU) system. It serves approximately 21,000 students, the majority of whom are first-generation college-goers (80\%), female (62\%), Hispanic (62\%), and Pell Grant recipients (63\%) (ir.csusb.edu). Eighty-five percent of the student population comes from the Inland Empire of Southern California, a diverse, economically depressed region that ranks last in terms of educational achievement among communities with more than 1 million residents (Brown, 2017). In aggregate, the four- and six-year graduation rates for our students are $12 \%$ and $55 \%$ respectively. The four- and six-year graduation rates for White students are $21 \%$ and 59\% and for students of color they are $10 \%$ and 53\%. Further disaggregation shows even greater disparity in outcomes for African-American students at $9 \%$ and $47 \%$. Such data indicates that CSUSB is precisely the kind of institution that needs to think about transformation in terms of equity and inclusion. It is a clear example of an institution that needs to proactively address the “opportunity gaps" for low-income students and students of color and to become the studentready campus its student population needs it to be.

The equity-minded transformation work currently being undertaken at CSUSB is part of the larger CSU system's Graduation Initiative 2025 (GI 2025), which aims to add 100,000 more baccalaureate degree-educated citizens to California by 2025 (CSU, 2017) and our campus's local efforts to convert from quarters to semesters (Q2S) in Fall 2020. The two initiatives are related because the Q2S conversion provides an opportunity for the faculty to completely rethink and realign the curriculum in more equity-minded and pedagogically sound ways. Given that CSUSB is a predominantly female, minority-serving institution, explicitly addressing equity issues as part of the Q2S curriculum transformation will undoubtedly work toward the goals of GI 2025. However, embedding attention to these concerns at the program, course, and facultystudent interaction levels in meaningful ways requires expertise regarding equity-minded teaching and learning that Bensimon's work suggests most faculty members to not necessarily possess.

The Q2S team has therefore leveraged the CSUSB administration's need to meet the Chancellor's Office GI 2025 goals to garner a significant amount of funding to encourage and support faculty to participate in professional learning opportunities intended to foster "equitymindedness"- - defined here as a way of thinking and practicing that draws attention to and seeks to actively address patterns of inequity in student outcomes - as part of the quarter to semester curriculum transformation process. More specifically, faculty members can choose to convert their programs by adapting their existing program to fit the new semester calendar and requirements or apply for a grant to completely transform their programs. Grant money is contingent upon faculty participation in learning opportunities that ask them to: a) study the scholarship regarding how people learn, including the impact that drawing on students' cultural wealth has on learning; b) think metacognitively about their disciplinary identities and disciplinary habits of mind and how this intersects with other aspects of their identities, such as their race, class, gender, religion, etc.; and c) explore and implement equity-minded, evidence- 
based teaching practices that allow students to bring their various identities to these disciplinary habits of mind in ways that might work toward a more equitable and inclusive culture and society. Before funds are dispersed, faculty must submit their new programs with a narrative that explains how the new program embeds equity-mindedness in its structure and how attention to equity in outcome, to closing the opportunity gap for poor students and student of color, will continually be assessed and addressed. To date, $80 \%$ of our programs have chosen to transform, which means that the vast majority of the faculty at CSUSB (including adjunct faculty members, who are also eligible for funding to participate in this community of practice) will engage in a significant amount of professional learning regarding equity-minded teaching by Fall 2020.

\section{Theoretical Framework for our Approach to Faculty Learning}

Much research and scholarship in the field of professional development has indicated that the traditional model of one-shot faculty professional development workshops is not substantive enough to foster the kind of systemic, equity-minded institutional change CSUSB seeks. Genuine transformation of this nature requires deep learning within and culture change among the faculty (Beach \& Cox, 2009; Cox, 2001; Desrocher, 2010; and Hubball and Beach, 2004). The literature regarding the science of learning suggests that deep, transformational learning for faculty, like deep, transformational learning for students, requires actively grappling with concepts, ideas and problems, organizing one's own knowledge and meaning-making related to these problems, and testing this new knowledge against one's prior knowledge over a sustained period of time with multiple opportunities for feedback, support, reflection, and revision (Bransford et al. 1999; Kober, 2015). This kind of intellectual work is absolutely consistent with faculty culture. This is important because the research regarding how institutions change (Kezar, 2014) suggests that meaningful change is more likely to come about if change agents intentionally work in ways consistent with the culture in which they are trying to make change. The approach to faculty learning geared toward equity-minded institutional transformation at CSUSB, therefore, is intellectually challenging, engaging and sustained; it acknowledges and leverages faculty members' identities as disciplinary experts who are used to developing their own scholarly inquiries in an effort to contribute to the knowledge-base of their fields. In short, it assumes that if scholars in our institution are expected to engage and learn and grow, in terms of their ability and willingness to teach in equity-minded ways and to serve as empowering agents for students, then the professional learning in which they participate must position them as scholarly learners who conduct scholarly inquiry into equity-minded teaching and learning in order to contribute to equity-minded institutional transformation in meaningful ways, over an extended period of time.

We have chosen to employ a community of practice model to structure our identity-based approach to faculty professional development and learning at CSUSB. Research shows that they have been used effectively in educational, business, and governmental sectors to "steward" knowledge within organizations and, in so doing, to profoundly transform institutions (Childs et al, 2011; Cox, 2005; OEAS et al, 2012; Reed, 2014; Wenger, 1999; and Wenger et al, 2002). Such effectiveness, however, largely depends on how they are designed. According to Wenger et al (2002), in order for a community of practice to sustain and develop learning and to "steward" knowledge throughout the institution in transformative ways, the community of practice must be designed for "aliveness." When designed appropriately, communities of practice are, and are viewed by the community, as relevant, valuable, and "alive" enough to continually attract new 
members, while continuing to engage more experienced members in deeper ways (Cox, 2005; OEAS et al, 2012; Reed, 2014; Wenger et al, 2002). According to Reed (2014), communities of practice are best cultivated by: “(1) allowing for organic evolution in their structures, (2) opening a dialogue among people with both inside and outside perspectives, (3) inviting different levels of participation over time and depending upon current topics, (4) providing both public and private community spaces, (5) focusing on the value of the community (likely both sharing problems and needs and building a body of knowledge), (6) combining familiarity and excitement, and (7) creating a rhythm for the community.”

The identity-conscious community of practice model of professional learning at CSUSB was created with these design principles in mind. It is intended to embody the social theory of learning as participation and to raise consciousness about how identity, power, and institutionalized racism, sexism and other oppressive power structures impact learning, opportunity and success. CSUSB's community of practice consists of a variety of professional development structures and activities — faculty learning communities (FLCs), mini-conferences, book clubs, speaker series, peer class visits and observations, and roundtable discussions - that allow for differing levels of participation. However, all focus in some way on these two core concepts/learning goals: a) learning requires active social participation that inevitably structured by power dynamics and asymmetries; and b) institutional racism, sexism, and other forms of institutionalized oppression impact learning, opportunity, and outcome. How faculty interact with students matters to the kind of impact these forms of injustice ultimately has. However, while all of the aforementioned activities are offered as part of the overall community of practice, the primary structure for faculty learning in CSUSBs model is the FLC.

In "Introduction to Faculty Learning Communities," Cox (2004) defines FLCs as groups of cross-disciplinary faculty who "engage in an active, collaborative, yearlong program with a curriculum about enhancing teaching and learning and with frequent seminars and activities that provide learning, development, the scholarship of teaching, and community building” (8). According to Beach and Cox (2009), when implemented with integrity, FLCs, compared to other forms of faculty development, are "more (a) structured, (b) intensive, (c) focused on completing the deliverables, (d) focused on the social aspects of building community, (e) focused on the scholarship of teaching and learning, and (f) focused on the team aspect while developing individual projects” (as reported in Desrocher (2010), p. 3). They break down silos, build community, provide a safe, supportive, and effective environment for faculty learning, and, in so doing, they have been shown to create the grassroots networks needed to create and sustain cultural shifts and systemic institutional change (Beach \& Cox, 2009; Cox, 2001; Hubball \& Beach, 2004).

While the FLC structure is the core of our community of practice model, the variety of activities mentioned above is necessary to keep the overall community of practice "alive." According to Wenger et al (2002), "alive” communities generally have three main levels of participation (1) a core group of people who take on leadership roles by "identify[ing] topics for the community to address and mov[ing] the community along its learning agenda"; (2) an active group who attends meetings regularly and occasionally takes on leadership roles; and (3) peripheral members, "who keep to the sidelines, watching the interactions and listening to the dialogues among the core and active members.” Rather than require particular levels of engagement or participation, successful 
communities of practice create opportunities for semiprivate interaction and learning that still has impact and might ultimately draw these members into more active participation.

Within the CSUSB model, the roundtables function to introduce and attract potential faculty participants to the questions, ideas, and activities central to the community of practice. These functions provide a venue for the active members to share their projects with more peripheral faculty members. They emphasize the value of the work of the community of practice both to the faculty participants themselves, as well as to the institution more generally. Similarly, full-day workshops serve to introduce faculty to the ideas and questions that will be more fully explored in the FLCs, by allowing workshop participants to experience equity-minded, evidence-based teaching practices and engage in discussion about them before committing to the time the FLCs demand. In addition to attracting new members, these activities, among others, such as brown bag lunches, also provide a way for faculty who have already participated in an FLC to stay connected to the project and to share and develop their expertise, even if they are not participating in a different FLC.

\section{The Inquiry-Based, Identity-Conscious Curriculum}

Given the active, participatory nature of learning and the commitment to scholarly inquiry that characterizes faculty culture, the two concepts at the core of our community of practice-1) learning requires active social participation that inevitably structured by power dynamics and asymmetries and 2) institutional racism, sexism, and other forms of institutionalized oppression impact learning, opportunity, and outcome; how faculty interact with students matters to the kind of impact these forms of injustice ultimately have-are not something we can simply tell faculty and then expect these ideas to significantly impact how faculty interact with their students both in and outside of their classrooms. Instead, we must engage faculty in scholarly inquiry around four essential questions that will reveal and reinforce those two key ideas in deep and meaningful ways. The four essential questions that explicitly guide our entire community of practice are:

1. How does learning work?

2. How can we make our disciplinary habits of mind, the ways of thinking and practicing that contribute to complex wicked problem-solving visible to students and invite them into our disciplinary communities in ways that allow them to integrate the identities, values, and commitments they bring with them with the new ways of thinking and doing that they are developing at the university?

3. What are equity-minded, high-impact, evidence-based curricular design and teaching practices and how can we implement them in ways that engage how people learn, foster disciplinary habits of mind and build from the cultural wealth and connections to community that our students bring with them to their university experience?

4. How can we change the discourse about student learning and success from what students can't do to what they can and will be able to do with our support, guidance, and apprenticeship?

As the facilitators of the professional learning opportunities provide resources and activities that enable faculty to explore each of these questions (as well as the ones they develop on their own, in the context of their own needs and interests), they bring attention to the roles that identity and 
power dynamics play in learning and in access to opportunity. They also ask faculty to reflect on their own identities, learning experiences, and access to opportunities and to bring the substance of these reflections to bear on the questions and curricular and pedagogical work they conduct as part of their participation in the community of practice.

\section{Threshold Concepts}

One resource the facilitators bring to many of our professional learning activities regarding curriculum and course design is Meyer and Land's (2006) notion of “threshold concepts.” According to Meyer and Land, threshold concepts refer to the ideas or concepts that are absolutely core to the ways of knowing and doing in a discipline. Mastery and use of these concepts is indicative of an individual's membership in a disciplinary community; it identifies them as a disciplinary expert (as, for example, a historian, a mathematician, a chemist, etc.). Conversely, if an individual does not understand these ideas well enough to use them, s/he cannot move forward in the discipline, will not be recognized as an "insider" within the community, and will be unable to credibly contribute to the field's knowledge base.

Many of the professional learning activities, particularly the FLCs, begin with a threshold concepts approach to curriculum design and pedagogy, because it is so intricately reflective of the research regarding how people learn. It engages faculty where their passion lies - in their discipline and content knowledge-and because by explicitly engaging the faculty members' disciplinary identities, it provides a nice bridge to talking about student identity, what it means to be a community "insider" or "outsider," what the markers are of "insider- and outsider-ness," and what it entails and sometimes costs to become an "insider." This then allows the facilitators and the participants to engage the more political and affective dimensions of learning, the role these dimensions can and should play in how we design our courses, assignments, and pedagogical approaches, and the impact they might have on the opportunity gap.

The way the topic is initially introduced is to ask faculty to read about the notion of threshold concepts and then, in order to engage their background knowledge before discussion and to establish reflection as a norm for our work, we ask them to reflect on their own learning, to describe an "ah-ha moment," or a shift in thinking. We also ask them to consider how and why such a shift was transformative and the impact this transformation has had on their identities, on the ways they see and interpret the world. The initial responses to these prompts are not usually very substantive, but participants revisit these same questions multiple times as we delve deeper into research about how people learn and the ways learning intersects with issues of power and identity. They also have the opportunity to develop them further throughout their professional learning experiences and to hear from other members of the community who may have considered these issues in a previous professional learning setting.

After this reflection, participants work in disciplinary groups to identify threshold concepts in their disciplines. They brainstorm a list individually first, then come together as a disciplinary group to identify a common one to focus on, and then to work through the characteristics of threshold concepts. They then describe for the other groups outside their discipline what the disciplinary threshold concept they have chosen is (what it actually means), why it is "troublesome” for students, what is “counterintuitive” about it, what a students' work might look 
like when they are in the process of productively grappling with the idea, but have not yet mastered it, what pedagogical moves an instructor might make to foster such mastery, and why, when mastered, the threshold concept is "transformative" and "irreversible."

Participant feedback from our FLCs indicate that faculty members generally find this activity useful and engaging and are surprised to discover that although these concepts are central to their fields, they rarely address them explicitly in their courses and curriculum. They see this as a "problem" that is somewhat easily addressed. From here, participants delve more deeply into how these threshold concepts shape disciplinary habits of mind, the ways of thinking and practicing in a discipline using Middendorf and Pace's (2004) "Decoding the Disciplines" model. More specifically, faculty participants reflect on their learning in graduate school and identify one assignment or project they needed to complete that was typical of the work they now do as a disciplinary expert, to describe how they approached the task (what they needed to do to address the task, how their approach evolved as they moved forward, etc.), and to identify what they needed to know, understand, and be able to do in order to engage productively in this work. Once they've reflected individually, faculty members share their responses with a partner outside of their field in a structured "pair-share" activity. The listening partner is to focus on and ask probing questions about the language his/her partner uses and processes that s/he describes that are unclear. Participants then regroup by discipline and share their responses and their experiences working with a partner outside their field, focusing on the similarities and differences in the task, approach, and required knowledge and skills, as well as on the language and processes their partners asked them to explain. These lists (of disciplinary problems, disciplinary ways of thinking and doing, and the knowledge and skills necessary to engage in this disciplinary work) form the basis for curriculum design, course design, signature assignments, supporting students' successful completion of signature work, and/or whatever the focus of the faculty learning community might be.

\section{The Shift to Equity}

As noted above, in the process of engaging faculty in these explorations, attention is paid to identity and to "insider-ness" and "outsider-ness"; faculty participants discuss the distance that must be crossed in order to become an insider, what one must acquire and give up in order to cross this distance, how the distance-the quantity and the quality of it--came to be. Participants further discuss how this often varies for different students based on their identities, and how we can best help students cross various disciplinary thresholds with dignity and without losing the connection to who they are and where they come from and who they would like to be and where they would like to go. In short, the FLC members begin to broach the topic of the role identity and power (including institutional racism, sexism, and other -isms) play in educational access and outcome and in learning more generally.

To support this exploration, participants are asked to describe, in a private, informal written reflection, how they think learning works, what supports it, and how these assumptions about learning are made manifest in their teaching practices. Facilitators then introduce Wenger's social theory of learning as participation and various frameworks for and research regarding how people learn. They ask participants to discuss each theory/framework individually, to identify similarities and differences, and to compare them to their pre-conceived ideas about how 
learning works. Once they follow-up on participants' questions and observations, they delve more deeply into the affective, social, and political dimensions of learning (Bransford et al.'s first principle regarding the need to surface and engage the knowledge, ideas and assumptions students bring with them and Schoenbach et al."s "personal” and "social” dimensions of learning) and the role identity, power, and politics play in learning, opportunity, and "success."

To begin these discussions, participants read articles or excerpts from books regarding the impact various forms of oppression can have on learning and engagement. They also explore the "deficit language" that pervades so much of the discourse in higher education regarding working class students and students of color, and discuss the negative impact this can have on faculty interaction with students both in and outside the classroom. Ultimately, the FLC explores the question McNair et al (2016) raise in Becoming a Student-Ready College about what a "studentready college" might look like and what it would mean to value students' cultural wealth, what they bring with them to the university, rather than to put the onus on students to be "collegeready" and to speak almost exclusively in terms of what they lack. In the process, faculty participants reflect privately on the ways in which their own identities and cultural wealth were or were not aligned with and valued in their own university experiences and how and why that might matter to the work they now do with students.

\section{Establishing Community Norms}

Engaging meaningfully in these conversations, going deeply enough to really uncover and engage honestly with some of the unconscious biases that shape how the participants think about and interact with their students, is not easy because it requires taking the notion of faculty as learners seriously. This means recognizing that people's prior experiences and knowledge will shape how they interact, engage with, and absorb material and creating space for this knowledge and experience to be brought to bear on the conversation at hand. Doing so often feels dangerous for different people, for different reasons. For example, we have had the experience where those who occupy more privileged positions deny or dismiss the ways that racism, sexism, and other systems of inequality influence learning, because they have not experienced it and/or because they cannot see it. Even if no one in the group explicitly takes this position, those who have and continue to experience the exercise of unequal power structures often say they fear that such denial and dismissal will happen. Experience has also shown that calling attention to the "deficit language" often used to describe students, to language many of the participants use and have used in conversation within the community of practice and elsewhere, can put some faculty members on the defensive, ultimately alienating them from the content and the community of practice. Those faculty members who share identities and experiences with the students being described in those deficit terms, those faculty members who themselves have and continue to experience racism, sexism, and other forms of oppression, may also feel further wounded and alienated. Losing members from either group (even if they stay, but disengage) means we limit the amount of genuine progress towards equitable transformation we can make as a campus.

In order to avoid this fate, and to create conditions in which productive engagement is most likely to take place, the facilitators try to name and engage these possible tensions prior to going into these conversations. At the outset of all of the professional learning work at CSUSB, we establish "community agreements" for the work we will do together. These agreements, 
generated in response to reflective prompts regarding participants' best and worst learning experiences and what made them so, usually include things like "be willing to take risks"; "stay present/be here”; “don't monopolize the conversation-watch your air time,” but on days when we know we are going to address the more difficult conversations about power, inequality, and social (in)justice, we intentionally revisit the community agreements we established earlier. We propose a version of the agreements that Singleton (2016) argues are necessary in order to have the kind of productive conversations about race that bring about equity in schools. According to Singleton (2016), participants in these conversations need to be willing to "stay engaged, experience discomfort, speak [their] truth, and expect and accept non-closure.” To help frame our conversations productively, then, we try to address the danger of disengagement upfront by proposing a variation on Singleton's agreements that we have found to be both productive and provocative. ${ }^{2}$ We put the following six agreements on the board and ask the participants to reflect privately on what they think each agreement means and why they might be relevant to a conversation about the role racism, sexism, and other forms of oppression in learning, at our institution, and in the world of higher education more generally:

1. No shame

2. No blame

3. No guilt

4. Call out "the ouch"

5. Stay engaged

6. Experience discomfort

During the discussion of their reflections on these agreements, and before the facilitators ask if they can be added to the pre-existing community agreements, participants often share their fear or experience of saying or having unknowingly said the "wrong thing" or having been misunderstood and feeling frustrated and guilty. Others have mentioned the frustration of needing to figure out whether and how to call out something they find racist or offensive in some way, of having to weigh both the personal and professional costs of "saying something" and then running the risk of, for example, being seen as or accused of being " the angry Black woman." This then leads to a discussion of why it might be important in this context to try to push through this, to what it would take to "stay engaged" and to "experience the discomfort" in order to make genuine progress toward our goal of a being a more equitable institution. Presenting these ideas and asking the participants to unpack them, before engaging in explicit conversation about the deficit language commonly used to describe so many of our students, creates a space to name what is likely to be in the air and something to point to as a way of opening a dialogue about what is happening in the room if/when things do get tense, but it still does not necessarily go far enough in preparing faculty members who are unfamiliar with a lot of the work around the role which identity, power and privilege plays in learning to engage at the level necessary to be truly transformative.

${ }^{2}$ A version of this strategy was introduced to me by my colleague Lauren Servais at Santa Rosa Junior College, who adapted it from the National SEED project (https://nationalseedproject.org/about-us). 
To help deepen participants' understanding, then, we also explicitly frame the conversation about deficit language and cultural wealth with an exploration of the notion of identity-consciousness. According to Singleton (2014), movement to a more racially just world requires that both people of color and white people develop racial consciousness, which entails a shift in thinking from "I don't know I don't know"/’I don’t know, but I think I do" to “I know I don’t know” to "I know I know.” Thus, after the conversation about adding the additional community agreements, facilitators present Singleton's claim and ask the faculty participants to reflect individually on what each of these stages might mean, to provide examples that might fall under each category and why, and to make connections between this kind of consciousness and the work we do with students. They also ask participants to think about how such consciousness-raising might be relevant to other aspects of identity and/or to the intersections of our multiple identity positions. From there, we engage in an experiential activity in which the facilitator asks a serious of questions and the participants respond to each prompt ${ }^{3}$. The responses include:

- I think most about this identity.

- I think least about this identity.

- I have the most fulfilling relationships with people with whom I share this identity.

- This aspect of my identity makes me feel shame.

- This aspect of my identity provides me the most access to wealth.

- This aspect of my identity has had the strongest impact on how I see myself.

- This aspect of my identity has had the greatest impact, positive or negative, on how others see me.

- I feel the most at ease with this aspect of my identity.

Debriefing this activity as a whole group entails asking the faculty participants what they noticed, what was difficult and/or easy about the exercise, what, if anything, made them uncomfortable and why they think these things were so, and what they learned. They are also asked to link any insights they gained from this activity to the previous conversation about the importance of identity consciousness to a more equitable and inclusive institution and to the role that identity and power play in learning, opportunity and success. Some of the most powerful insights have come from participants who are willing to share how difficult it is to admit to some of their colleagues that they have never thought about any of this before and how different it must be to move through the world feeling the need to (or being free of the need to) think about how others perceive you and trying to account for or subtly counter such unspoken assumptions. This has often led to conversations about Dubois' (1903/1996) notion of double-consciousness, the notion of unconscious bias, and back to Steele's notion of stereotype threat and the impact this can have on faculty interaction with students and student success more generally.

These conversations also often lead to discussion about the ways unconscious bias is not only reflected in the deficit language often used to describe our students, but also in our own interactions with students and within interactions among the students in our classes. This leads to

3 This activity and these prompts were developed by my colleague Evelyn Knox. 
a larger discussion of the role identity and power plays in classroom dynamics, in how we might structure the classroom, our syllabi, our assignments, and the moves we make in the classroom when we operate with more identity consciousness: what issues do we need to think about? What questions or issues do we need to address? In short, what can we, as instructors, do to dismantle the types of power imbalances that often prevent marginalized students from succeeding to their fullest potential?

Within the context of this conversation, we also revisit the notion of threshold concepts and their reflections about why these might be troublesome and/or why the irreversible transformation they bring about might be problematic for some students. We talk about ways to help students see and/or create connections between the identities student bring with them, the communities to which they already belong, and the disciplinary communities they wish to join and the work they hope to do. With all of these conversations in mind, we then ask faculty to identify an evidencebased teaching practice that they would like to study and implement, one they think might help students engage productively with the threshold concepts in their field and is consistent with what they now understand about how learning works in all of its complexity. We then support them to implement it in identity-conscious and equity-minded ways, by asking them to continually reflect on the following questions and discuss these reflections with other members of the community of practice:

- What opportunities are you creating for students to engage in authentic disciplinary (and interdisciplinary) problem-solving?

- How are you making the threshold concepts that shape these disciplinary habits of mind explicit?

- How are you supporting students' understanding of these concepts? How are you engaging the knowledge and assumptions they bring with them? How are you building from their cultural wealth?

- What formative feedback and other pedagogical moves are you making to support the recursive nature of learning, as students attempt to cross these disciplinary thresholds?

- How are you asking them to organize their knowledge and integrate their learning?

- What opportunities are you providing for them to think metacognitively about their learning and to engage in metacognitive conversation?

- How are you ensuring that all voices are included and heard in the classroom?

- How are you inviting students into this work and helping them to see/imagine themselves as authentic, authorized members of the disciplinary community?

- How are you helping them to see/make connections between who they are and who they wish to become and to navigate the conflicts inherent to this process?

Of course, all of this content cannot be fully addressed or explored in any one particular professional learning opportunity. Thus, as noted before, we offer a variety of professional learning structures and activities within the overall community of practice: faculty learning communities (FLCs), mini-conferences, book clubs, speaker series, peer class visits and observations, and roundtable discussions that allow for differing levels of participation, but all focus in some way on the ideas and questions outlined above. 


\section{Impact}

It is too soon to measure the impact our community of practice is having on graduation rates and in closing the opportunity gap for poor students and students of color at CSUSB because much of the revised courses and curriculum will not be implemented until Fall 2020, when the campus converts to semesters. That said, we are beginning to see evidence of the growth of such a grassroots network dedicated to equity-minded institutional transformation in the increased participation in the various professional learning activities that make up our community of practice. In the last year of the traditional "one-shot” workshop model of professional learning on our campus, the number of total faculty participants in professional learning opportunities was 107. The first year we began to implement faculty learning communities as part of a larger, more coherent community of practice model, the number grew to 176 . The year we began implementing greater attention to identity, diversity, equity, and inclusion and their relationship to teaching and learning, the number was 193. In the last two years, since work on GI 2025 and Q2S has begun, the numbers of faculty participants are 421 and 726 respectively. These numbers indicate our community of practice is very much "alive", interest is growing, and participation is ongoing. In keeping with Wenger's idea of differing levels of participation, we are also now seeing many faculty members who participated in earlier FLCs taking on leadership roles by facilitating their own FLC and by participating in a "Facilitator Learning Community," an FLC that explores best practices for designing and implementing faculty professional development.

In addition to this increasing and ongoing participation in the community of practice, participants' comments and reflections on their experience in our community of practice and the impact it is having on their teaching now, even before the semester curriculum work can be implemented, suggests that we are well on our way to transforming our institution into a more inclusive and equitable learning environment. When asked immediately after participation in an FLC about their learning, participants noted that they had learned "strategies for fostering more equitable interaction and engagement of students," "ways to think about bias and perspective differently and how this is relevant to [their] teaching," and "how to teach for depth, rather than breadth, that it's worth taking the time to get students to engage on a personal and interactive level." Two years later, when the same group of faculty participants was asked to reflect on how their work in the community of practice has impacted their work with students, we received the following comments:

Through exposure to issues of microaggressions, bias and understanding better what is meant by social justice, I find myself trying to address these issues in all of the classes that I teach. An example of how what I learned in the Institute has affected my teaching is I now start every class talking about how different perceptions that result from our different identities and experiences are brought to the study of all phenomenon. I use the exercise we did for this in all my classes with an object from home. It tends to get all the students thinking about their own bias and it is a great place to start every class.

The institute helped me to recognize that I am guilty of unconscious bias. As a junior faculty member, I am constantly reflecting on my own teaching practices and looking for ways I can improve. It was eye opening to see that my own unconscious bias can affect how I teach and how I may unknowingly exclude a group of students from a class 
discussion. After the institute, I have tried to be more conscious of my behavior in my interactions with students.

Redesigning this course through scaffolding and approaching the design by working backwards through the big course learning outcomes has changed my perspective on how I teach all of my courses. I think it is important to have the big picture in mind and it is important for the students to get to the point where they can see the big picture. Part of this big picture relates to what students should really get out of college and how each class I teach can contribute to this outcome. As a mathematics teacher, diversity has not always been a big part of my curriculum. However, this institute and the incorporation of ideas concerning diversity into the course redesign has really opened my eyes to the important opportunities I have to impart a perspective onto my students as they continue their journey to become more aware of their diverse environment and their actions within it. This, I feel, is such an important outcome for our students as they progress through college. Thus, it really should be an important outcome for my students as they progress through my class.

While these comments suggest that the faculty members, two years after their original participation in an FLC (referred to here as the "institute") continue to see an impact on their work with students, we realize these assessments are informal and indirect. One FLC, funded by the National Science Foundation (NSF) Widening Implementation and Demonstration of Evidence-Based Reforms (WIDER) grant no. 1347671, was more formally evaluated as part of the grant work. The community was dedicated to studying and implementing evidence-based teaching practices in large STEM courses and to developing a strategic plan for increasing the understanding and use of evidence-based teaching methods within the College of Natural Sciences. The external evaluation of this grant found that the project was:

successful at creating an active and intensive Faculty Learning Community [...] All FLC participants reported that the experience had been extremely valuable for them, particularly the community aspect of the FLC. [...] Observations confirmed that FLC members were actively using their chosen strategies in the daily implementation of their classes, as well as a variety of student learning support strategies and instructional techniques to meaningfully engage students in course material. [...] The majority of students rated the piloted courses highly. In particular, most students felt that their instructor was well-prepared, responsive to students, enthusiastic about their teaching, and successful at creating an environment that was conducive to learning. [...] FLC members identified a number of changes in their students related to their EBTPs (evidence-based teaching practices) including increased engagement, a more positive learning environment, deeper thinking, communication skill development, higher final grades, and more positive attitudes toward STEM disciplines.

The strategic plan developed as part of this grant by the FLC members has led to a new five-year NSF Improving Undergraduate STEM Education (IUSE) grant, which will extend the work begun as part of the WIDER project on evidence-based teaching. The new project will have a much greater emphasis on identity, equity, and inclusion and to closing the opportunity gap for students in the STEM fields. Funds from this grant will be used to evaluate the impact of the 
project on student success. Evaluation will help us to better understand, evaluate, and assess the impact of our identity-conscious community of practice on the institution as a whole and the extent to which it has transformed into a more equitable and inclusive learning environment.

\section{Conclusion}

The work at CSUSB is predicated on the notion that robust faculty learning is required for equity-minded institutional change. The model described here stands in stark contrast to the "one-shot" workshop model that has historically characterized faculty development in higher education. Indeed, CSUSB's nascent community of practice for faculty professional learning asks the faculty participants to reflect on their own learning, identities, and experiences; to draw on these reflections to develop and research answers to these questions; to experience and engage in the kind of equity-minded, evidence-based teaching practices they are exploring; to reflect metacognitively on their engagement with these practices; to develop curricula and assignments based on this work in their own classrooms; and to give and receive feedback on these assignments and their implementation from facilitators and their peers.

In the end, what unifies this identity-conscious community of practice is a desire to transform the institution into a more inclusive and equitable space. In this renewed institution, all students are prepared to bring their identities, interests, and experiences, along with multiple disciplinary lenses and approaches, to the unscripted questions, problems, and tasks that define the $21^{\text {st }}$ century. In keeping with the theory of learning as social participation at the heart of community of practice model, we create space for faculty participants to co-construct the knowledge discovered, developed and shared within the community of practice. Doing so, while modeling the kind of equity-minded teaching practices and interactions we hope our faculty will engage in with our students, is key not only to keeping the community of practice alive, but also to enabling it to function as a driver of the institutional change we hope to effect. 


\section{References}

Beach, A. L., \& Cox, M. D. (2009). The impact of faculty learning communities on teaching and learning. Learning Communities Journal, 1(1), 7-27. Retrieved from http://celt.miamioh.edu/lcj/

Bensimon, E.M. (2007). The underestimated significance of practitioner knowledge in the scholarship on student success. The Review of Higher Education, 30(4), 441-469. Retrieved from https://www.press.jhu.edu/journals/review-higher-education https://doi.org/10.1353/rhe.2007.0032

Bransford, J.D., Brown, A.L., and Cocking, R.R. (Eds.) (1999). How People Learn: Brain, Mind, Experience, and School. Washington D. C.: National Academy Press.

Brown, C. (2017). Why we must help Inland Empire students escape poverty. Press Enterprise. 24 June. Retrieved from http://www.pe.com/2017/06/24/why-we-must-help-inland-empirestudents-escape-poverty/

Cole, D. \& Espinoza, A. (2008). Examining the academic success of Latino students in science, technology, engineering and mathematics (STEM) majors. Journal of College Student Development, 49(4), 285-300. https://doi.org/10.1353/csd.0.0018

Cousin, G. (2006). An introduction to threshold concepts. Planet, 17(1), 4-5. https://doi.org/10.11120/plan.2006.00170004

Cox, A. (2005). What are communities of practice? A comparative review of four seminal works. Journal of Information Science, 3(6), 527-540. https://doi.org/10.1177/0165551505057016

Cox, M. D. (2001). Faculty learning communities: Change agents for transforming institutions into learning organizations. In D. Lieberman \& C. Wehlburg (Eds.), To improve the academy: Resources for faculty, instructional, and organizational development 19, 69-93. Boston, MA: Anker. https://doi.org/10.1002/j.2334-4822.2001.tb00525.x

CSU Graduation Initiative. (2017, January 3). Retrieved from http://graduate.csuprojects.org. CSUSB, Office of Institutional Research. (2017, January 3). Retrieved from http://ir.csusb.edu.

Desrochers, C. G. (2010). Faculty learning communities as catalysts for implementing successful small-group learning. In J. Cooper \& P. Robinson (Eds.), Small Group Learning in Higher Education: Research and Practice, 1-17, Stillwater, OK: New Forums Press.

DuBois, W.E.B. (1996). The Oxford W.E.B. DuBois Reader. New York, NY: Oxford University Press.

Elrod, S., \& Kezar, A. (2016). Increasing Student Success in STEM: A Guide to Systemic Institutional Change, Washington, D.C.: AAC\&U. 
Hubball, H., Clarke, A., \& Beach, A. L. (2004). Assessing faculty learning communities. New directions for teaching and learning, 2004(97), 87-100. https://doi.org/10.1002/tl.136

Kezar, A. (2014). How Colleges Change: Understanding, Leading, and Enacting Change. New York, NY: Routledge.

Kober, N. (2015). Reaching Students: What Research Says about Effective Instruction in Undergraduate Science and Engineering. Washington D.C., National Academies Press.

MacPhee, D., Farro, S., \& Canetto, S.S. (2013) Academic self-efficacy and performance of underrepresented STEM majors: gender, ethnic, and social class patterns. Analysis of Social Issues and Public Policy, 13(1), 347-369. https://doi.org/10.1111/asap.12033

McNair, T.B, Albertine, S., Cooper, M.A., McDonald, N. \& Major, T. (2016). Becoming a Student-Ready College: A New Culture of Leadership for Student Success. San Francisco, CA: Jossey-Bass.

Meyer, J.H. \& Land, R. (2006). Overcoming Barriers to Student Understanding: Threshold Concepts and Troublesome Knowledge. New York, NY: Routledge.

Middendorf, J. \& Pace, D. (2004). Decoding the disciplines: A model for helping students learn disciplinary ways of thinking. New Directions for Teaching and Learning, 2004(98), 1-12. https://doi.org/10.1002/tl.142

Office of Educational Access and Success (OEAS), Center for Advanced Communications Policy, and Center for 21st Century Universities. (2012). Development of virtual communities of practice to support programmatic efforts within university systems: Some considerations and recommendations. OEAS Working Paper Series \#12-01.

Ouellett, M. (2005). Teaching Inclusively: Resources for Course, Department * Institutional Change in Higher Education. New York: New Forums Press.

Pendakur, V. (2016). Closing the Opportunity Gap: Identity-Conscious Strategies for Retention and Student Success. Sterling, VA: Stylus Press.

Reed, J. H. (2014). Communities of Practice: A Tool for Creating Institutional Change in Support of the Mission of the Federal Energy Management Program. Federal Energy Management Program, U.S. Department of Energy.

Schneider, C.G. (2015). The LEAP Challenge: Transforming for Students, Essential for Liberal Education. Liberal Education. Retrieved from https://www.aacu.org/liberaleducation/2015/winter-spring/schneider 
Schoenbach, R., Greenleaf, C., \& Murphy, L. (2012) Reading for Understanding: How Reading Apprenticeship Improves Disciplinary Learning in Secondary and College Classrooms. San Francisco, CA: Jossey-Bass.

Singleton, G.E. (2015). Courageous Conversations about Race: A Field Guide for Achieving Equity in Schools. Thousand Oaks, CA: Corwin.

Steele, C.M. (2010). Whistling Vivaldi: How Stereotypes Affect Us. New York, NY: W.W. Norton \& Co.

Umbach, P.D. \& Wawrzynski, M.R. (2005). Faculty Do Matter: The Role of College Faculty in Student Learning and Engagement. Research in Higher Education, 46(2), 153-184.

https://doi.org/10.1007/s11162-004-1598-1

Wenger, E. (2000). Communities of Practice: Learning, Meaning, and Identity. Cambridge, UK: Cambridge University Press.

Wenger, E., McDermott, R., and Snyder, W. (2002). Cultivating Communities of Practice: A Guide to Managing Knowledge. Boston, MA: Harvard Business School Press.

Yosso, T.J. (2005). Whose culture has capital? Race, Ethnicity and Education, 8(1), 69-91. Retrieved from http://www.tandfonline.com/toc/cree20/current 


\section{Author Information}

Dr. Kimberly A. Costino is Director of Semester Conversion and Professor of English at California State University, San Bernardino (CSUSB). She has also served as Director of CSUSB's Teaching Resource Center, as Co-Director of 3CSN's, “Threshold Project,” and as HUB Director for the California Faculty Collaboratives Project. Her research interests include literacy and cultural studies and critical race theory; she is particularly interested in the politics of literacy and access to higher education.

Kimberly A. Costino

CSU, San Bernardino

5500 University Parkway

San Bernardino, CA 92407

Email: kcostino@csusb.edu

Telephone: 909-537-7412 